\title{
BMJ Open Bridging gaps to promote networked care between teams and groups in health delivery systems: a systematic review of non-health literature
}

\author{
Jeffrey Braithwaite
}

To cite: Braithwaite J. Bridging gaps to promote networked care between teams and groups in health delivery systems: a systematic review of nonhealth literature. BMJ Open 2015;5:e006567.

doi:10.1136/bmjopen-2014006567

- Prepublication history and additional material is available. To view please visit the journal (http://dx.doi.org/ 10.1136/bmjopen-2014006567).

Received 23 October 2014 Revised 6 July 2015 Accepted 27 August 2015

CrossMark

Australian Institute of Health Innovation, Centre for Healthcare Resilience and Implementation Science, Macquarie University, Sydney, New South Wales, Australia

Correspondence to Professor Jeffrey Braithwaite; jeffrey.braithwaite@mq.edu.au

\section{ABSTRACT}

Objectives: To assess non-health literature, identify key strategies in promoting more networked teams and groups, apply external ideas to healthcare, and build a model based on these strategies.

Design: A systematic review of the literature outside of healthcare.

Method: Searches guided by Preferred Reporting Items for Systematic Reviews and Meta-Analyses (PRISMA) of ABI/INFORM Global, CINAHL, IBSS, MEDLINE and Psychinfo databases following a mindmapping exercise generating key terms centred on the core construct of gaps across organisational social structures that uncovered 842 empirical articles of which 116 met the inclusion criteria. Data extraction and content analysis via data mining techniques were performed on these articles.

Results: The research involved subjects in 40 countries, with 32 studies enrolling participants in multiple countries. There were 40 studies conducted wholly or partly in the USA, 46 wholly or partly in continental Europe, 29 wholly or partly in Asia and 12 wholly or partly in Russia or Russian federated countries. Methods employed included 30 mixed or triangulated social science study designs, 39 qualitative studies, 13 experimental studies and 34 questionnairebased studies, where the latter was mostly to gather data for social network analyses. Four recurring factors underpin a model for promoting networked behaviours and fortifying cross-group cooperation: appreciating the characteristics and nature of gaps between groups; using the leverage of boundary-spanners to bridge two or more groups; applying various mechanisms to stimulate interactive relationships; and mobilising those who can exert positive external influences to promote connections while minimising the impact of those who exacerbate divides.

Conclusions: The literature assessed is rich and varied. An evidence-oriented model and strategies for promoting more networked systems are now available for application to healthcare. While caution needs to be exercised in translating outside ideas and studies, drawing on non-health ideas is useful in providing insights into other sectors.

\section{Strengths and limitations of this study}

- This is a large systematic review of the nonhealth literature applying strategies originating outside of healthcare to counterbalance healthcare insularity and for learning to develop more connected, networked systems of care.

- It creates a model for facilitating networks.

- It provides strategies stakeholders can adopt to increase networked collaboration between and across teams and groups.

- Findings need to be interpreted with caution, as always when applying ideas and evidence from other sectors to healthcare.

\section{BACKGROUND}

Introduction

Healthcare has been criticised, implicitly or explicitly, for being inward-looking. ${ }^{1-3}$ There are exceptions to this general rule. Attempting to apply aviation knowledge to medicine, ${ }^{4-6}$ generic quality-improvement methods to health systems ${ }^{7} 8$ and basic science techniques to medical research ${ }^{9}$ are cases in point. A failure to resort to ideas, theories or evidence from outside the sector can lead to claims of tunnel vision, blinkeredness or insularity. Those who have difficulty exploiting external solutions may be unduly resistant, merely uninformed or using defensive routines ${ }^{10}{ }^{11}$ aimed to protect the status quo or to save face in the light of external evidence that could otherwise alter their practice or worldview. ${ }^{12}$ Recent work argues for the importance of going outside healthcare to understand the mechanics of its networking. ${ }^{13}$ Relatively new ideas have been imported from or influenced by other sectors, including interprofessionalism ${ }^{14} \quad 15$ and its close cousin multidisciplinarity, ${ }^{16} \quad 17$ systems thinking, ${ }^{12}{ }^{18}$ 'small world' 
networks, ${ }^{19}$ culture-change models ${ }^{20}$ and teamwork ${ }^{21} 22$ (eg, through virtual teams ${ }^{23-25}$ ).

There are many examples from sociology or systems theory which can be drawn on to understand networking, or more broadly, to promote collaborative concepts. Table 1 provides definitional guidance for the key terms used. Of particular interest, Weick's original idea of tight and loose coupling, ${ }^{26}{ }^{27}$ for instance, raises attention to the relative flexibility or rigidity of organisational structures. To understand coupling, Weick hypothesised that events, departments, groups and other organisational entities can be tightly bound or more loosely connected depending on the cultural characteristics of the organisation, the technical rules imposed on people and the extent to which those in authority attempted to induce tightness or looseness. In tightly coupled organisations, the tendency is to be rules-governed, prescriptive and to operationalise control mechanisms. In loosely coupled organisations, people have more scope to exercise discretion and may be relatively autonomous decisionmakers.

Taking a different but related track, early network theorist Granovetter ${ }^{28}$ examined the ties between people in networks. In social network theory, people are depicted as nodes and the connections between them as lines between the nodes. People can be connected directly (one degree of separation between them) or less directly (two or more degrees of separation between them). Those with strong ties between them are those who are typically connected closely, who know each other within a group, or who have first order relationships. They directly know, relate to and deal with each other. Weakly tied people are less directly connected. They are acquaintances, those on 'nodding' terms, and friends-of-friends-those who can be sought out for help or information beyond people's immediate social circles.

\section{The problem and attempts to induce more networked behaviours to date}

What is common among the competing theoretical paradigms, such as Weick's and Granovetter's hypotheses, is the degrees of connectivity or extent of fragmentation between networking or potentially networking groups. Effective communication and relations across organisational teams and groups are by no means universal. In healthcare, the professional divides, ${ }^{29}{ }^{30}$ entrenched subcultures, ${ }^{31} 32$ organisational silos, ${ }^{33} 34$ isolated cliques, uncommunicative teams, poorly relating groups, and disconnected wards, units and departments ${ }^{35} 36$ are often the norm. Unfortunately, examples of effectively networked or collaborative care in health settings, such as Wagner's chronic care model, ${ }^{37}{ }^{38}$ the patient-centred medical home ${ }^{3940}$ and local initiatives, such as the collaborative care model for Alzheimer disease,${ }^{41}$ are relatively isolated instances, but exemplify how more joined-up behaviours can be encouraged.

The popular response in health settings to address this type of problem, involving attempts to induce greater levels of networking, has been to study, promote or induce teams or microsystems, ${ }^{42}$ fortify within-group cooperation, ${ }^{43}$ nurture better internal relationships ${ }^{44}$ or promote productive, trusting interactions. ${ }^{45}$ There have also been attempts in some health sectors to encourage clinical networks across delivery systems. ${ }^{46-49}$ However, progress has been slow. There remain many striking examples of fragmented healthcare organisations and systems,${ }^{50-52}$ poorly performing services ${ }^{53}$ or dysfunctional cultures. ${ }^{54}$ Few, if any, healthcare policymakers, managers, clinicians or researchers have failed to experience these. Fragmentation is also evident in sectors outside healthcare, but there are also studies of interconnected systems and studies of networking from these sectors. These can inform the thinking of healthcare insiders, and are the focus of this paper.

\section{Aims}

To apply learning from other sectors to healthcare, the paper takes a specific focal point. Intensifying efforts to create better internal teamwork does not logically improve cross-team behaviours. Building connected systems of care is likely to need greater understanding of behaviour at the edges of, and gaps between, teams and groups, rather than how well they work internally. The legendary quality improvement thinker W Edwards Deming's ninth point in his 14 key principles for organisational transformation in Out of the crisis $^{7}$ is the exhortation to "break down barriers between departments". The aim, therefore, is to figure out how to join groups together collaboratively across pre-existing divides and barriers. There are sporadic examples of how to do this in healthcare. ${ }^{13} 355657$ However, this is a wicked problem, and more work is needed.

A recent review of between-group behaviour in healthcare identified 13 studies, ${ }^{35}$ concluding that fragmented systems and services are prevalent, and that individuals with roles that promote interaction across teams and groups, such as clinical opinion leaders or those with high levels of sociability, represent potential forces in forging greater levels of connectivity. In order to document a wider range of ideas and possibilities, this review builds on that work and the research it synthesised by examining non-health literature on gaps, disconnections, weak ties, social spaces and structural holes between teams and groups on the one hand, and the edges and boundaries of these on the other. The aim is to identify and apply lessons on cross-group activities from outside the health sector. Following this, a model will be developed to provide insights into how to promote more joined-up, networked care.

\section{METHODS}

\section{Literature search}

Systematic review procedures adopted conform to the Preferred Reporting Items for Systematic Reviews and Meta-Analyses (PRISMA) guidelines ${ }^{58}$ and have been 
Table 1 Definitions

Term
Absent tie
Between-group
behaviour
Boundaries
Boundary spanners
Bridges
Cliques
Collaboration

Collaboration in healthcare

\section{Connectors \\ Cooperation \\ Cosmopolites \\ Coupling}

Degrees of separation

\section{Disconnections \\ Edges}

Fragmentation

\section{Gaps}

Groups

Identity

Influence

Integration

Interactive relationships Joined-up healthcare

\section{Liaisons \\ Loose coupling}

\section{Mavens}

Microsystems

Networking, social

Networks, social

Opinion leaders Organisational silo Reciprocity theory

Social identity theory

Social networks Social space Strong tie

\section{Definition}

Where individuals or groups are in close proximity but remain disconnected, or have the opportunity to connect, but do not do so

The activities and psychological relationships across two or more groups-closely related to the concept of intergroup dynamics

The perimeters of a social entity (SE), differentiating those who belong and those who do not. Language, dress, and rituals are often used to create boundaries

People who bridge two or more SEs, enabling exchange of information or communication Those who span otherwise isolated SEs

Small inclusive circles of people with shared interests, who systematically exclude outsiders The act of working together over time to share information, knowledge or resources in order to achieve mutual aims, goals or objectives

This can be construed at several levels: cooperative, joint effort manifesting across departments, wards and units; across professional groupings of doctors, nurses and allied health professionals; across relationships between clinicians, managers and policymakers; across healthcare organisations or sectors; or across macro, meso and micro components of the system People linking two or more SEs

Working together to meet mutual aims in a more short term superficial manner than collaboration Persons with wide-ranging interests and interactions

Links, connections or pairings between individuals or groups; these can be tight or loose

The number of connections between any two people. The famous phrase 'six degrees of separation' refers to the theory that any person on earth is no more than six steps away from any other person

Disjunctions, breaks, inconsistencies or disparities between two or more SEs

The borders or outside limits of an SE

The splintering or breaking up of groups often on the basis of politics, or differing cultural or subcultural perspectives

The spaces, breaks or openings between two or more SEs

Individuals conjoined or located proximally, or considered or classed together as an SE, typically sharing a common identity and creating mutually recognised obligations

The group's or person's conceptualisations of their individuality, affiliations or characteristics

The capacity or actuality of exercising power in order to shape, control or manipulate something or someone

Where individual and group effort is coordinated, and the usual barriers to collaboration or cooperation have been reduced

The members of two or more SEs interfacing, mingling or exchanging information

Collaborative, integrated efforts across formal or informal organisational or service boundaries to thereby tackle shared issues

People who shuttle between SEs, enabling relations and communication

The somewhat detached or distant connections, links and relationships between individuals and groups. When social entities are loosely coupled there is said to be a degree of flexibility

Folks with a wide circle of contacts across multiple SEs

Small-scale ecological components of a larger system within which people work, interact and network

The practice of extending connections or relationships among pre-existing or new, or weak or strong ties in social systems

Sets of connections, relationships or ties among individuals. Social structures comprising nodes representing individuals or groups describing relationships and flows of information between them Influential individuals to whom others turn to for advice or information

A bounded organisational arrangement with limited interaction with other groups, units or divisions People will respond in kind to others. Positive examples are gift exchange or returning acts of kindness with kindness; negative examples are retaliation or returning hurtful acts equivalently An account suggesting that people's self-concept is grounded in their views about their membership of one or more social groups. This is reflected in how they behave, how they identify with others and understand themselves

A group of interconnected people who exchange information, resources, contacts or experience The gaps, holes or weak ties between SEs Where two or more individuals or groups are directly connected in a close relationship 


\begin{tabular}{ll} 
Table 1 Continued & Definition \\
\hline Term & $\begin{array}{l}\text { Interpersonal gaps in networks; in Burt's theory, they provide opportunities for players in } \\
\text { competition to bridge the discontinuities and create social capital or improved relationships with } \\
\text { other players } \\
\text { Structural holes }\end{array}$ \\
$\begin{array}{l}\text { Within a larger culture, a smaller group differentiating from the larger host culture with } \\
\text { distinguishable beliefs, interests or behaviours }\end{array}$ \\
Subculture & $\begin{array}{l}\text { People coworking interdependently, sharing accountabilities, meeting the needs of their customers } \\
\text { and themselves by purposefully accomplishing goals. When performing effectively, teams are seen }\end{array}$ \\
Teams & $\begin{array}{l}\text { as performing such that their outcomes are greater than the sum of the performance of individual } \\
\text { members }\end{array}$ \\
Teamwork & $\begin{array}{l}\text { The combined activities of a group of people working effectively toward common ends } \\
\text { "The third who enjoys": the party who benefits from competing or quarrelling with others } \\
\text { "The third who joins": the party who connects network members }\end{array}$ \\
Tie & $\begin{array}{l}\text { Connections between people (individuals or groups) such that they can readily share or transmit } \\
\text { information, culture, goodwill or enmity }\end{array}$ \\
Tight coupling & SEs which are closely adjacent or tightly connected to each other. Tightly coupled groups are \\
typically seen as rules-bound and prescriptive & The way players respond to others, particularly in game theory, with equivalent retaliation \\
Tit-for-tat & Faith, belief or confidence in the reliability, truth, capacity or ability of someone \\
Trust & Those with whom people are relatively poorly connected, for example, acquaintances \\
Weak ties &
\end{tabular}

documented elsewhere. ${ }^{13} 59$ A comprehensive literature review aiming to assess papers published until June 2012 was conducted by interrogating the ABI/INFORM Global, CINAHL, IBSS, MEDLINE and Psychinfo electronic literature databases since their inception, closely following a published guide to systematic reviews in healthcare. ${ }^{59}$ By utilising brainstorming techniques, a mind-mapping exercise, previous research, ${ }^{13}$ and a preliminary review of the literature, the following search terms were generated: 'social boundar*', 'group boundar*', 'network boundar*', 'social network boundar*', 'social group boundar*', 'liminal boundar*', 'social edge*', 'group edge*', 'network edge*', 'social network edge*', 'social group edge*', 'liminal edge*', 'social space*', 'group space*', 'network space*', 'social network space*', 'social hole*' and 'structural hole*'. Selection criteria restricted the target references, depending on database, to 'human', 'English language' and 'scholarly journals'. 13

\section{Literature review}

Citations, abstracts and complete references that where available were downloaded into Endnote X5, a bibliographic software management package. Of the 9025 references found in the search, 7908 remained after duplicates were removed and these were narrowed further to 842 research articles by excluding non-empirical work. All empirical research designs were included to provide an overview of the types of studies being conducted. The sample of references was further refined by subjecting these to scrutiny by three independent researchers. The articles had to fulfil three criteria: including work specifically related to cross-social groupings and clusters (eg, teams, groups and networks) in social spaces (eg, structural holes, weak ties and gaps), at the borders (eg, edges, boundaries) and in specific places (eg, in industries, organisations, communities, schools and churches). All papers were assessed against the inclusion criteria by two reviewers (JT and DD initially, and in a second round, by JB and DM, see acknowledgements), who assessed study quality and met to reconcile any disagreements, discussing these until consensus was reached.

\section{Literature analysis}

The remaining references which met the inclusion criteria $(n=219)$ were then further restricted to 2005-June 2012, emphasising relative recency. Apart from some older papers that were considered key to the topic area, two papers were added via snowballing $(n=129)$, and the sample separated into health $(n=13)$ and non-health $(n=116)$ subsets. The review of the health literature was published ${ }^{35}$; the systematically-oriented review of the non-health literature is the subject of this paper.

\section{RESULTS}

\section{Content analysis}

A Leximancer content analysis ${ }^{60}$ applying data mining techniques to the 116 research papers yielded key concepts (table 2) and themes (figure 1), identifying the number of times each concept was used, indicating how widespread it prevailed in the literature and its relevance to the overall sample. Concepts in the Leximancer terminology (see table 2) are clusters of words that relate together, similar to those that would be found in a thesaurus. Themes are groups of concepts sharing commonalities or connectedness. Thus, concepts are more fine grained and themes are more broad language 
Table 2 Ranked list of key concepts and connectivity in the literature on organisational social spaces, networks, boundaries and holes

\begin{tabular}{|c|c|c|c|c|c|}
\hline Concepts & Count & Relevance (\%) & Concepts & Count & Relevance (\%) \\
\hline Network & 4851 & 100 & Technological & 900 & 19 \\
\hline Social & 3656 & 75 & Collaboration & 899 & 19 \\
\hline Capital & 3506 & 72 & Practice & 884 & 18 \\
\hline Knowledge & 3260 & 67 & Contacts & 860 & 18 \\
\hline Research & 2467 & 51 & Behaviour & 846 & 17 \\
\hline Used & 2384 & 49 & & & \\
\hline Study & 2316 & 48 & Market & 831 & 17 \\
\hline Information & 2309 & 48 & Terms & 825 & 17 \\
\hline Related & 2200 & 45 & Public & 822 & 17 \\
\hline Work & 2070 & 43 & Form & 819 & 17 \\
\hline Group & 2014 & 42 & Systems & 813 & 17 \\
\hline Management & 2012 & 41 & Units & 799 & 16 \\
\hline Different & 2008 & 41 & Context & 795 & 16 \\
\hline Organisation & 1805 & 37 & Integration & 770 & 16 \\
\hline Relationships & 1785 & 37 & Approach & 770 & 16 \\
\hline Individuals & 1731 & 36 & Design & 755 & 16 \\
\hline Ties & 1712 & 35 & Significant & 744 & 15 \\
\hline Structure & 1695 & 35 & Task & 744 & 15 \\
\hline Positive & 1660 & 34 & Impact & 740 & 15 \\
\hline Effects & 1648 & 34 & School & 732 & 15 \\
\hline Sharing & 1519 & 31 & Following & 726 & 15 \\
\hline Members & 1417 & 29 & Service & 722 & 15 \\
\hline Process & 1404 & 29 & Building & 709 & 15 \\
\hline Interactions & 1386 & 29 & Others & 709 & 15 \\
\hline Learning & 1378 & 28 & Community & 709 & 15 \\
\hline Time & 1320 & 27 & Paper & 702 & 14 \\
\hline Identity & 1295 & 27 & Particular & 688 & 14 \\
\hline People & 1264 & 26 & Negative & 687 & 14 \\
\hline Employees & 1252 & 26 & Theory & 676 & 14 \\
\hline Performance & 1238 & 26 & Boundaries & 663 & 14 \\
\hline Support & 1225 & 25 & Transfer & 662 & 14 \\
\hline Business & 1211 & 25 & Control & 659 & 14 \\
\hline Activities & 1177 & 24 & & & \\
\hline Innovation & 1176 & 24 & & & \\
\hline Case & 1132 & 23 & Power & 634 & 13 \\
\hline Team & 1132 & 23 & Identities & 631 & 13 \\
\hline Available & 1113 & 23 & Common & 628 & 13 \\
\hline Role & 1106 & 23 & Local & 608 & 13 \\
\hline Organisational & 1099 & 23 & Environment & 605 & 12 \\
\hline Model & 1094 & 23 & Education & 592 & 12 \\
\hline Data & 1087 & 22 & Trust & 592 & 12 \\
\hline Analysis & 1085 & 22 & $\mathrm{De}$ & 589 & 12 \\
\hline Including & 1079 & 22 & Students & 585 & 12 \\
\hline Resources & 1078 & 22 & Government & 575 & 12 \\
\hline Development & 1074 & 22 & Perspective & 567 & 12 \\
\hline Communication & 1051 & 22 & Policy & 561 & 12 \\
\hline Industry & 1026 & 21 & Places & 561 & 12 \\
\hline Culture & 1020 & 21 & Spaces & 552 & 11 \\
\hline Project & 1018 & 21 & Workplace & 522 & 11 \\
\hline Experience & 1014 & 21 & Economic & 506 & 10 \\
\hline Participants & 987 & 20 & Software & 502 & 10 \\
\hline Cooperation & 964 & 20 & Sense & 491 & 10 \\
\hline Personal & 939 & 19 & National & 451 & 09 \\
\hline Example & 930 & 19 & Global & 408 & 08 \\
\hline Change & 918 & 19 & Academic & 406 & 08 \\
\hline Value & 909 & 19 & Social & 397 & 08 \\
\hline Based & 904 & 19 & White & 203 & 04 \\
\hline
\end{tabular}


Figure 1 Map of key themes in the literature on organisational social spaces, networks, boundaries and holes. clusters. In the Leximancer thematic map of the literature (figure 1), each circle is a theme and each dot a concept, with the connecting lines illustrating how related they are.

The central concepts and themes show that the literature repeatedly discusses networks, social, capital and knowledge in social context, emphasising collaboration and cooperation. It is centrally about communication, work and activities, and their management in groups or organisations.

\section{Systematically-oriented review}

The 116 studies were systematically reviewed. Full papers were assessed by two independent researchers (JB and DM, see acknowledgements) and a random sample checked by a third (CW, see acknowledgements) and the key features abstracted (see online supplementary table S1). Common themes were identified using grounded theory, following the procedure outlined by Glaser and Strauss. ${ }^{61}$ The researcher and supporting reviewer (JB and DM, see acknowledgements) assessed the papers until these themes emerged as the most commonly occurring premises.

The research involved subjects in 40 countries, with 32 studies enrolling participants in multiple countries. This literature includes 40 studies conducted wholly or partly in the USA, 46 wholly or partly in continental Europe, 29 wholly or partly in Asia and 12 wholly or partly in Russia or Russian federated countries. Methods employed included 30 mixed or triangulated social science study designs, 39 qualitative studies using various social science methods (interviews, ethnography, focus groups), 13 experimental studies (in psychology laboratories, for the most part) and 34 questionnaire-based studies, the last category mostly to gather data for social network analyses. Many studies were theoretically informed, particularly concerning group and team theories, and many drew on constructs from social network theory. 


\section{DISCUSSION}

Overall, this research synthesised wide-ranging studies centred on the core constructs of networks, gaps and fragmentation across gaps in organisational settings. What does it indicate to those hoping to induce more productive networked structures, and apply that knowledge to healthcare?

\section{The literature in perspective}

Understanding how teams and groups interact across their boundaries, through formal and informal members operating at the edges and relating to each other to a greater or lesser extent collaboratively or competitively, is a crucial phenomenon to understand. Organisational gaps and boundaries underpin the mechanisms by which behaviours, practices, attitudes and values spread; how innovation diffuses and cultural characteristics permeate into systems; and how ideas, knowledge and messages translate and migrate across systems and subsystems. ${ }^{62-65}$ Barriers and obstacles to creating joined-up teams and groups are omnipresent. ${ }^{31} 323456$ In one study, obstacles manifested as three types-psychological, situational and social-and women perceived more barriers to networking across teams and groups than did men. ${ }^{66} 67$

Taken together the results show that, as a general rule, teams and groups tend to promote an inwardly-focused identity. Strong in-group norms and behaviours operate within teams and groups. People not only identify with the group to which they belong, but their psychological well-being is often bolstered by their membership, particularly if their group is perceived to be prestigious or beneficial to them. ${ }^{68}$ Members will collectively draw mental or physical boundaries around themselves, circumscribing their group. People also perennially favour their group: the manifestation of in-group bias is strong and seemingly ubiquitous. ${ }^{69}$ Professions and organisational units, for example, almost always support and favour internal members over their counterparts in external professions or units. Indeed, who is in or eligible for membership, and who is not is in large part what defines a team or group. The phenomenon does not stop there. Teams and groups seem to be characterised by tacit or explicit knowledge about their membership or who is eligible for membership, and can readily identify those who are not members. ${ }^{69}$ This poses considerable problems for those seeking to encourage networked behaviours and collaborative structures.

People then align themselves, and identify closely with their own team or group. ${ }^{70}$ Teams and groups often demand or uphold loyalty from members. Deviants or those who are antigroup or antisocial can be subject to various forms of punishment ${ }^{71}$ such as being frowned on, gossiped about, left out, shunned or treated as being disloyal. These, among other determinants signifying identity, can lead to strong 'us and them' perspectives vis à vis other groups. Outgroups are often treated indifferently, unsympathetically or suspiciously. ${ }^{68} 7273$ There can be prejudice, enmity or even hostility between groups. ${ }^{69} 74$ All told, this state-of-affairs calls for active strategies to promote collaboratively-oriented systems. However, can disparate teams and groups actually be joined-up by active agency into more expansive networks?

\section{A four-factor framework for collaboration across teams and groups}

From the literature assessment and content analysis, a framework synthesising and integrating the current state of knowledge was derived. Figure 2 provides four core factors for appreciating networked efforts: understanding the nature of gaps, using the leverage of boundary spanners, stimulating interactive relationships and exerting power via external influences. These were frequently occurring common factors embedded implicitly or accounted for explicitly in the included literature. Within each factor, various strategies with utility for sponsoring networked collaboration across teams and groups are evident.

The figure depicts two social entities interfacing each other across an organisational divide. These could be, for example, two wards or two organisational units; or a group of doctors interfacing with another group of doctors; or a group of nurses or allied health professionals, working adjacent to each other. They are bounded, and will have greater or lesser levels of communication, connectivity or interactivity between themselves across the social space delineating them as separate groupings. The question is how to bridge the gap and thereby, help to promote networked connectivity. With that in mind, we turn to a brief description of the four factors and how these operate according to the synthesised studies in the non-health literature. This provides us with lessons about networking and how it operates elsewhere.

The nature of gaps (social or physical spaces, structural holes, disconnected ties) between teams and groups can be characterised and this information used to help join-up those who are unduly divided. Gaps can clearly act as barriers to knowledge and information exchange. ${ }^{63}$ However, gaps can also be useful: structural holes in networks, ${ }^{78} 79$ for example, offer opportunities for bridging behaviours. Once these gaps are recognised, people can begin to act to close gaps between teams and groups. All in all, a moderate level of spacing between teams and groups in complex social systems seems optimal in promoting interaction. ${ }^{80}$ Too many gaps or too wide the spacings between groups can indicate disunity or disintegration, which makes it hard to enhance linkages. Too few gaps, and narrowness increases the risk of poorly formed localised identities or the system being overconstrained, with no breathing space between the team or group. Building effective relationships across gaps or structural holes looms ${ }^{78} 7982$ as an important activity in joining-up teams and groups. Collaboration and partnerships can be encouraged by 


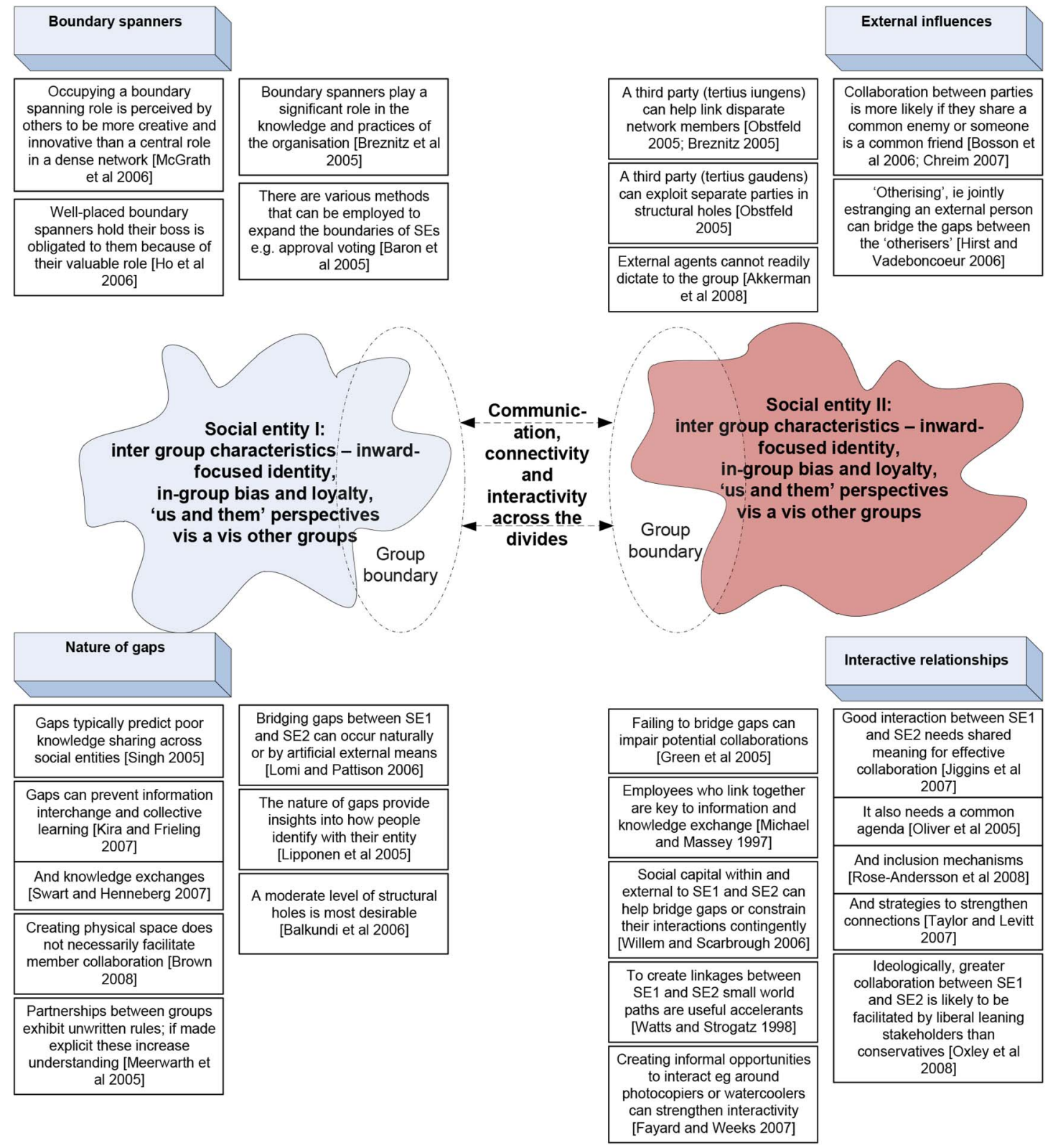

Figure 2 A conceptual framework for networked behaviours.

understanding the nature of the outgroup and intergroup behaviours, ${ }^{68}$ and the unwritten rules between groups such as those that inform each potential partners' views on their own and the others' strengths, limitations and capabilities. ${ }^{83}{ }^{84}$ Wenger's work on communities of practice $^{8586}$ and its application ${ }^{8788}$ is a case in point.

Boundary spanners depending on the circumstances can bridge two or more groupings, and enable exchange and communication. Such roles are often highly regarded and those occupying them can make a valuable contribution in promoting connections between people and groups. ${ }^{89}$ Useful initiatives to promote boundary crossing include: identifying those with facilitation skills, ${ }^{90}$ or encouraging potential bridge-builders (those who span or straddle otherwise isolated teams and groups), connectors (people actively linking two or more teams and groups), liaisons (people who shuttle between teams and groups, enabling relations and communication), mavens (folks with a wide circle of contacts), opinion leaders (influential individuals to whom others turn to for advice or information) or cosmopolites (persons with wide-ranging interests and interactions). However, boundary spanners, in the process of fulfilling their role by bridging gaps inevitably alter relationships, and by their efforts to join-up two previously divided groups can create different boundaries and gaps elsewhere. Interestingly, liberal-leaning rather than conservative-leaning individuals are more likely to bridge gaps or boundary span, and advance collaborative activities. ${ }^{91}$ Gatekeepers play an important protective role in healthcare. For example, in some countries, general practitioners prevent patients from unnecessarily 
entering specialised healthcare and being over-serviced. However gatekeepers, ${ }^{92}$ blockers and manipulators can inhibit boundary-spanning behaviours. They need to be identified and their negative influences negated or minimised if networked, collaborative behaviours are to be realised.

This leads to the challenge of how to stimulate interactive relationships. Recurring ideas in the literature include: building joint social capital by emphasising mutual goodwill across teams and groups; ${ }^{74} 93$ formally linking otherwise disparate groupings together, ${ }^{92}$ providing informal opportunities to inter-relate, ${ }^{77} 94$ including creating commonly-available public space in which to intermingle $;^{25} \quad{ }^{95}$ promoting dialogue and shared meaning between groups; ${ }^{96}$ agreeing on joint agendas; ${ }^{97}$ striving for inclusivity; ${ }^{9} 99$ supporting social diversity ${ }^{100}$ and generally encouraging, over time, connections and exchanges between teams and groups. These strategies can, depending on the circumstances, strengthen communication and information exchange. Leaders who support informal social activities and promote social ties, for example, after-work activities, can improve productivity and particularly, intergroup functioning and performance. ${ }^{101}$ People who have strong relationships across teams and groups, and are embedded in the larger organisational culture are less likely to signal an intention to leave their organisation, ${ }^{102}$ and this can be important in building long-term connectivity. Trust is an important commodity in linking teams and groups: ${ }^{103-105}$ so building up of trust is an important endeavour. Taken together, these strategies can help connect teams and groups. The right strategy-mix will need to be determined by formal and informal leaders and members of the teams and groups themselves, and are often defined by the context.

External influences can also play a bridging or dividing role. A tertius iungens agent ('the third who joins') who builds bridges can help facilitate group interaction, but a tertius gaudens agent ('the third who enjoys') can exacerbate existing divides, exploiting these for his or her own benefit. ${ }^{7879} 106$ While there is some support for the notion that outsiders cannot readily dictate to teams and groups, ${ }^{67}$ other work suggests that group members who share a common enemy ${ }^{107} 108$ or jointly emphasise their distance from or aversion to other groups, thereby differentiating themselves, ${ }^{109}$ will be more likely to collaborate with each other. This has been a long held belief: if, as the old Arab proverb states, "the enemy of my enemy is my friend" then it is also likely to be the case that "my friend's enemy is my enemy". Whether or not this is so, teams or groups sharing a negative attitude about or a perceived threat from a third party will be likely to move closer to each other. ${ }^{107}$

\section{Some key theoretical perspectives}

Various theoretical perspectives can be mobilised to explain these empirical findings and the four-factor model. We have specifically encountered two: Weick's tight-loose coupling helps us to understand the extent to which characteristics, such as rules or discretion, are at work in having greater or lesser effects on connectivity between teams and groups. Granovetter's strong and weak ties asks whether people adjoining each other are in a direct relationship, or more distant from each other, that is, merely acquaintances. Either theory can help to some extent illuminate networked patterns of behaviour, and suggest mechanisms to strengthen interactions.

Two other theoretical accounts stand out in further explaining the model. The phenomenon of 'us and them' is a subset of social identity theory, ${ }^{108} \quad 110-112$ which suggests that humans have strong self-concepts tied to needs for belongingness with those in their in-group, and seek to identify with, be part of or embrace the attitudes and behaviours of their fellow group members. Consequences foreshadowed by social identity theory include robust bias in favour of the in-group, and preferential treatment for fellow members. In-group members are often seen to be estranged from, prejudiced about, competing with, scapegoating or even hating those in out-groups. Clearly, there can be strong pressures or motivations to affiliate with one's group and to distrust, treat warily or actively dislike other groups. Antidotes, such as those described in the conceptual framework for networking (figure 2), will likely need concerted, longitudinal effort to tackle 'us and them' feelings and behaviours. Even then, gains are not likely to be huge.

Another mechanism underpinning networking is described by reciprocity theory, also known as tit-for-tat, ${ }^{113} 114$ which predicts that teams and groups will retaliate equivalently. Tit-for-tat theory suggests that the way group members treat those in other groupings, whether badly or well, is more than likely to be reciprocated. This is exemplified by many game theory studies $^{100}$ and much of the literature from the earliest time period, for example, "do unto others as you would have them do unto you" and "an eye for an eye and a tooth for a tooth". Successive iterations of reciprocity can readily hard-wire into collaboration or hostility. This phenomenon is strongly related to trust. ${ }^{77} 115 \mathrm{An}$ optimal response pattern for collaboration across teams and groups seems to be: always start relationships cooperatively, do not be the first to defect, and practise forgiveness when wronged. ${ }^{114}$

Of course, there are other theoretical accounts which could be developed to help understand groups' relationships. These include explaining how some teams or groups come to be especially good at connecting with nearby teams or groups compared with others who are not; the mechanisms of affiliation across teams and groups when it spontaneously occurs; specifying how one group comes to be dominant and another subservient; and concepts of mutuality versus rivalry, manifesting most frequently as cooperation versus competition. Each of these is likely to be fruitful to a greater or lesser extent in contextualising the relationships between 
teams and groups, and could be useful gateways to further research.

\section{The nature of gaps and boundaries, and applications in healthcare}

The core ideas of gaps, boundary spanners, interactive relationships and external influences found in the literature review are very well suited to the analysis of healthcare. There are concrete implications for healthcare settings.

Gaps interfering with joined-up services, a key feature of health systems, are very hard to bridge. Gaps can be the physical area between one department and another, the silos operating to structurally delineate medicine, nursing and allied health staff or the temporal divides that separate two or more groups working shifts. These can also emerge as the conceptual gulf between the attitudes of people in one part of the healthcare organisation or system and another. Gaps often manifest as the cultural differences demarcating one unit or professional group ('us') and the other ('them'). All organisations create barriers and partitions which inhibit or prohibit collaboration because of specialisation, myopic internal focus or tribalism. Problems arise where this interferes with effective organisational functioning or the delivery of good care.

Boundaries are phenomena of interest if we have to learn to bridge gaps and create better networked systems of care. Boundaries can be sharp and obvious, as between hospitals and nursing homes or amorphous and unclear, as when two or more organisational groupings remain as separate entities, but share resources, leaders, staff or physical space (eg, different specialists; physicians and nurses; or day and night shift staff). In healthcare there are formal organisational gaps, that is, 'you are department A and we are department E', and physical or location gaps, that is, 'we work here and you, behind that partition, across the corridor, on another floor, or in another building, are over there'. There are conceptual gaps, manifesting in differentiable mental models, that is, 'you think that way, but we don't'. And there are behavioural gaps, as in 'this is how we dress, speak, and practise, compared with you'. Gaps can be emotional, for example, two teams who have come to detest each other and are poles apart, or conceptually different, as in the gap between achieving a 'personal best' in a team developing a new model of care and a rival teams' normal, everyday performance. However, categorised gaps and boundaries distinguish teams and groups, and define where one ends and another begins. For those seeking to influence the health system to thereby create networked care, these gaps and boundaries should not be ignored. Instead, by identifying the nature of gaps and boundaries, we can begin to focus on the efforts that are needed to join them up, and create more synergistic effort to improve care for the benefit of patients. This is perhaps the major lesson to take home from this review.

\section{LIMITATIONS}

Systematic reviews including this one are limited by the constraints of the inclusion criteria, in this case the terms and the date of the review period (2005-June, 2012). Applying ideas from other settings to healthcare may pose challenges.

\section{CONCLUSIONS}

This systematically-oriented review provides an assessment of a large volume of non-health literature, presenting a four-factor model and strategies for translating insights and ideas to the health sector. It sought to facilitate access to external thinking as an antidote to health sector insularity, and as a way of understanding how to build more connected, networked systems of care. While caution is warranted in translating unmediated ideas and evidence from other sectors to healthcare, drawing on outside ideas to tackle hard problems is useful in at least providing insights and seem to be overdue.

These findings may be of benefit to healthcare stakeholders seeking greater levels of networked collaboration. However, no one should doubt the immense challenges facing those seeking to build more productive networking across healthcare delivery systems.

Acknowledgements The original literature searching and reviews, and the Leximancer analyses were conducted in conjunction with my brilliant colleagues Dr Joanne Travaglia (JT) and Dr Deborah Debono (DD). Ms Danielle Marks (DM) provided invaluable research assistance, as did Mr Chris Wu (CW), and Dr Brette Blakely reviewed an earlier manuscript for readability. They have my sincere appreciation.

Funding This research was supported under Australian Research Council's Linkage and Discovery Projects funding schemes (project numbers LP0 775514 and DP0986493), and National Health and Medical Research Council's programme grants in patient safety (programme APP568618 and APP1054146). No funding bodies had any role in the design, data collection and analysis, decision to publish or preparation of the manuscript.

Competing interests The author has completed the ICMJE uniform disclosure form at http://www.icmje.org/coi_disclosure.pdf and declares: the author had financial support from grants from Australian Departments of Health; the National Health and Medical Research Council; and from the Department of Industry and Science-Australian Research Council, during the conduct of the study.

Ethics approval Ethics approval for our research is held at University of New South Wales, and Macquarie University, Australia.

Provenance and peer review Not commissioned; externally peer reviewed.

Data sharing statement No additional data are available.

Open Access This is an Open Access article distributed in accordance with the Creative Commons Attribution Non Commercial (CC BY-NC 4.0) license, which permits others to distribute, remix, adapt, build upon this work noncommercially, and license their derivative works on different terms, provided the original work is properly cited and the use is non-commercial. See: http:// creativecommons.org/licenses/by-nc/4.0/

\section{REFERENCES}

1. Braithwaite J. Hunter-gatherer human nature and health system safety: an evolutionary cleft stick? Int J Qual Health Care 2005;17:541-5.

2. Christensen C, Grossman J, Hwang J. The innovator's prescription: a disruptive solution for health care. New York: McGraw-Hill, 2009. 
3. Helmreich R. On error management: lessons from aviation. BMJ 2000;320:781-5

4. Morey J, Simon R, Jay G, et al. Error reduction and performance improvement in the emergency department through formal teamwork training: evaluation results of the MedTeams project. Health Serv Res 2002;37:1553-81.

5. Salas $\mathrm{E}$, Wilson $\mathrm{K}$, Burke $\mathrm{C}$, et al. Does crew resource management training work? An update, an extension, and some critical needs. Hum Factors 2006;48:392-412.

6. Hamman W. The complexity of team training: what we have learned from aviation and its applications to medicine. Qual Saf Health Care 2004;13:i72-9.

7. Deming W. Out of the crisis. MIT Press, 1986

8. Juran J. Quality control handbook. New York: McGraw-Hill, 1951

9. Patel $\mathrm{H}$, Arya M, Shergill I. Basic science techniques in clinical practice. London: Springer-Verlag, 2007.

10. Argyris C, Schön D. Organizational learning: a theory of action approach. Addison-Wesley, 1978.

11. Schein E. Process consultation. Vol. 1. Addison-Wesley, 1988.

12. Sterman JD. Learning from evidence in a complex world. $A m \mathrm{~J}$ Public Health 2006:96:505-14.

13. Braithwaite J, Debono D, Travaglia J. Social space and boundaries in organisational studies: a review of the literature. In. Sydney: Centre for Clinical Governance Research, 2009.

14. Braithwaite J, Westbrook J, Foxwell AR, et al. An action research protocol to strengthen system-wide inter-professional learning and practice [LP0775514]. BMC Health Serv Res 2007;7:144.

15. Astor $\mathrm{H}$, Rhoades $\mathrm{H}$, Sanson $\mathrm{A}$. Enhancing inter-professional relationships in a changing family law system: final report. In. Melbourne: The University of Melbourne, 2008.

16. Lambert $\mathrm{H}$, McKevitt $\mathrm{C}$. Anthropology in health research: from qualitative methods to multidisciplinarity. BMJ 2002;325:210-13.

17. Youngblood D. Multidisciplinarity, interdisciplinarity, and bridging disciplines: a matter of process. J Res Pract 2007;3:M18.

18. Hillman $\mathrm{K}$, Braithwaite $\mathrm{J}$, Chen $\mathrm{J}$. Healthcare systems and their (lack of) integration. In: DeVita MA, Hillman K, Bellomo R. eds. Textbook of rapid response systems. New York: Springer, 2011:79-86.

19. Watts DJ, Strogatz SH. Collective dynamics of 'small-world' networks. Nature 1998;393:440-2.

20. Braithwaite J, Hyde P, Pope C. eds. Culture and climate in health care organizations. London: Palgrave Macmillan, 2010.

21. Ellis AP, Bell BS, Ployhart RE, et al. An evaluation of generic teamwork skills training with action teams: effects on cognitive and skill-based outcomes. Personnel Psychol 2005;58:641-72.

22. Senior B, Swailes $\mathrm{S}$. The dimensions of management team performance: a repertory grid study. Int $J$ Productivity Perform Manag 2004;53:317.

23. Mihhailova G. Virtual teams: just a theoretical concept or a widely used practice? Bus Rev Camb 2007;7:186.

24. Mihhailova G. Management challenges arising from the use of virtual work. Baltic J Manag 2009;4:80

25. Au Y, Marks A. Virtual teams are literally and metaphorically invisible. Employee Relations 2012;34:271-87.

26. Weick KE. The collapse of sensemaking in organizations: the Mann Gulch disaster. Adm Sci Q 1993;38:628-52.

27. Weick KE. Educational organizations as loosely coupled systems. Adm Sci Q 1976;21:1-19.

28. Granovetter M. The strength of weak ties. AJS 1973;78:1360-80.

29. Hunter $\mathrm{D}$. The changing roles of health care personnel in health and health care management. Soc Sci Med 1996;43:799-808.

30. Battles J. Safety by design: quality and safety by design. Qual Saf Health Care 2006;15:11-3.

31. Braithwaite J, Westbrook M. Rethinking clinical organisational stuctures: an attitude survey of doctors, nurses and allied health staff in clinical directorates. J Health Serv Res Policy 2005;10:10-17.

32. Degeling P, Kennedy J, Hill M. Mediating the cultural boundaries between medicine, nursing and management-the central challenge in hospital reform. Health Serv Manage Res 2001;14:36-48.

33. Leape L, Berwick D, Clancy C, et al. Transforming healthcare: a safety imperative. Qual Saf Health Care 2009;18:424-8.

34. Curtis J, Shannon S. Transcending the silos: toward an interdisciplinary approach to end-of-life care in the ICU. Intensive Care Med 2006;32:15-17.

35. Braithwaite J. Between-group behaviour in health care: gaps, edges, boundaries, disconnections, weak ties, spaces and holes. A systematic review. BMC Health Serv Res 2010;10:330.

36. Braithwaite J. An empirical assessment of social structural and cultural change in acute settings. Health Care Anal 2006;14:185-93.
37. Coleman K, Austin BT, Brach C, et al. Evidence on the Chronic Care Model in the new millennium. Health Aff (Millwood) 2009;28:75-85

38. Wagner EH, Austin BT, Von Korff M. Organizing care for patients with chronic illness. Milbank Q 1996;74:511-44.

39. Reid RJ, Fishman PA, Yu O, et al. Patient-centered medical home demonstration: a prospective, quasi-experimental, before and after evaluation. Am J Manag Care 2009;15:e71-87.

40. Rittenhouse DR, Shortell SM. The patient-centered medical home: will it stand the test of health reform? JAMA 2009;301:2038-40.

41. Callahan CM, Boustani MA, Unverzagt FW, et al. Effectiveness of collaborative care for older adults with Alzheimer disease in primary care: a randomized controlled trial. JAMA 2006;295: 2148-57.

42. Mohr J, Batalden P. Improving safety on the front lines: the role of clinical microsystems. Qual Saf Health Care 2002;11:45-50.

43. West MA, Wallace M. Innovation in health care teams. Eur J Soc Psychol 1991;21:303-15.

44. Batalden P, Stoltz P. A framework for the continual improvement of health care: building and applying professional and improvement knowledge to test changes in daily work. Jt Comm J Qual Improv 1993;19:424-47; discussion 448-52.

45. Gilson L. Trust and the development of health care as a social institution. Soc Sci Med 2003;56:1453-68.

46. Braithwaite J, Goulston K. Turning the health system $90^{\circ}$ down under. Lancet 2004;364:397-9.

47. Cunningham FC, Ranmuthugala G, Westbrook Jl, et al. Net benefits: assessing the effectiveness of clinical networks in Australia through qualitative methods. Implement Sci 2012;7:108.

48. Edwards N. Clinical networks. BMJ 2002;324:63.

49. Addicott R, McGivern G, Ferlie E. The distortion of a managerial technique? The case of clinical networks in UK health care. Br J Manag 2007;18:93-105.

50. Davies $\mathrm{H}$, Nutley $\mathrm{S}$, Mannion R. Organisational culture and quality of health care. Qual Saf Health Care 2000;9:111-19.

51. Fortin S. The paediatric clinic as negotiated social space. Anthropol Med 2008:15:175-87.

52. Walshe K, Shortell S. When things go wrong: how health care organizations deal with major failures. Health Affairs 2004;23: 3103-11.

53. Goddard M, Mannion R, Smith P. Enhancing performance in health care: a theoretical perspective on agency and the role of information. Health Econ 2000;9:95-107.

54. Mannion R, Davies H, Marshall M. Cultures for performance in health care. Maidenhead: Open University Press, 2005.

55. MacMahon J, MacCurtain S, O'Sullivan M. Bullying, culture and climate in health care organizations: a theoretical framework. In: Braithwaite J, Hyde P, Pope C. eds. Culture and climate in health care organizations. London: Palgrave Macmillan, 2010.

56. Wikström E. Boundary work as inner and outer dialogue: dieticians in Sweden. Qual Res Organizations Manag: An Int J 2008;3:59-77.

57. Cook R, Render M, Woods D. Gaps in the continuity of care and progress on patient safety. BMJ 2000;320:791-4.

58. Moher D, Liberati A, Tetzlaff J, et al. PRISMA Group. Preferred reporting items for systematic reviews and meta-analyses: the PRISMA Statement. BMJ 2009;339:b2535.

59. Travaglia J, Braithwaite J, Debono D. Protocol for the rapid assessment, conceptualisation and timely, concise analysis of the literature [PRACTICAL]. Sydney: Centre for Clinical Governance Research, University of New South Wales, 2008.

60. Travaglia J, Westbrook M, Braithwaite J. Implementation of a patient safety incident management system as viewed by doctors, nurses and allied health professionals. Health 2009;13:277-96.

61. Glaser B, Strauss A. The discovery of grounded theory: strategies for qualitative research. Chicago: Aldine, 1967.

62. Gosling AS, Westbrook JI, Braithwaite J. Clinical team functioning and IT innovation: a study of the diffusion of a point-of-care online evidence system. J Am Med Inform Assoc 2003;10:244-51.

63. Singh J. Collaborative networks as determinants of knowledge diffusion patterns. Manage Sci 2005;51:756.

64. Christakis N, Fowler J. The spread of obesity in a large social network over 32 years. N Engl J Med 2007;357:370-9.

65. Keizer K, Lindenberg S, Steg L. The spreading of disorder. Science 2008;322:1681-5.

66. Tonge J. Barriers to networking for women in a UK professional service. Gend Manag 2008;23:484

67. Akkerman S, Petter C, de Laat M. Organising communities-ofpractice: facilitating emergence. J Workplace Learn 2008;20:383.

68. Lipponen J, Helkama K, Olkkonen ME, et al. Predicting the different profiles of organizational identification: a case of shipyard subcontractors. J Occup Organ Psychol 2005;78:97. 
69. Efferson C, Lalive R, Fehr E. The coevolution of cultural groups and ingroup favoritism. Science 2008;321:1844-9.

70. Schwarz G, Watson B, Callen V. Talking up failure: how discourse can signal failure to change. Manag Commun Q 2011;25:311-52.

71. Herrman B, Thöni C, Gächter S. Antisocial punishment across societies. Science 2008;319:1362-7.

72. Gächter S, Renner E, Sefton M. The long-run benefits of punishment. Sci 2008;322:1510.

73. Henrich J, McElreath R, Barr A, et al. Costly punishment across human societies. Science 2006;312:1767-70.

74. Willem A, Scarbrough H. Social capital and political bias in knowledge sharing: an exploratory study. Human Rel 2006;59:1343.

75. Kira M, Frieling E. Bureaucratic boundaries for collective learning in industrial work. J Workplace Lear 2007;19:296.

76. Swart J, Henneberg SC. Dynamic knowledge nets-the $3 \mathrm{C}$ model: exploratory findings and conceptualisation of entrepreneurial knowledge constellations. J Knowledge Manag 2007;11:126.

77. Zhou S, Siu F, Wang M. Effects of social tie content on knowledge transfer. J Knowledge Manag 2010;14:449-63.

78. Burt R. Structural holes: the structure of competition. Cambridge: Harvard University Press, 1992.

79. Burt R. The network structure of social capital. In: Sutton R, Staw B. eds. Research in organizational behaviour. Greenwich: JAI Press, 2000

80. Balkundi P, Kilduff M, Barsness Zl, et al. Demographic antecedents and performance consequences of structural holes in work teams. J Organ Behav 2007;28:241-60.

81. Schleimer S, Riege A. Knowledge transfer between globally dispersed units at BMW. J Knowledge Manag 2009;13:27-41.

82. Smedlund A. Characteristics of routine, development and idea networks in teams. Team Perform Manag 2010;16:95-117.

83. Meerwarth T, Briody E, Kulkarni D. Discovering the rules: folk knowledge for improving GM partnerships. Human Organ 2005;64:286

84. Lupina-Wegener AA, Schneider SC, Rolf van D. Different experiences of socio-cultural integration: a European merger in Mexico. J Organ Change Manag 2011;24:65-89.

85. Wenger E. Communities of practice: learning, meaning, and identity. New York: Cambridge University Press, 1998.

86. Wenger E, McDermott R, Snyder W. Cultivating communities of practice. Boston, Massachusetts: Harvard Business School Press, 2002.

87. Ranmuthugala G, Plumb JJ, Cunningham FC, et al. How and why are communities of practice established in the healthcare sector? A systematic review of the literature. BMC Health Serv Res 2011;11:273-89.

88. Soubhi $\mathrm{H}$, Bayliss EA, Fortin $\mathrm{M}$, et al. Learning and caring in communities of practice: using relationships and collective learning to improve primary care for patients with multimorbidity. Ann Fam Med 2010;8:170-7.

89. Ho V, Rousseau D, Levesque L. Social networks and the psychological contract: structural holes, cohesive ties, and beliefs regarding employer obligations. Human Rel 2006;59:459.

90. Wickramasinghe $V$, Weliwitigoda $P$. Benefits gained from dimensions of social capital: a study of software developers in Sri Lanka. Info Technol People 2011;24:393-413.

91. Oxley D, Smith K, Alford J, et al. Political attitudes vary with physiological traits. Science 2008;321:1667-70.

92. Michael J, Massey J. Modeling the communication network in a sawmill. Forest Prod J 1997:47:25.

93. Bosworth G. Education, mobility and rural business development J Small Bus Enterprise Dev 2009;16:660-77.
94. Fayard AL, Weeks J. Photocopiers and water-coolers: the affordances of informal interaction. Organ Stud 2007;28:605-34.

95. Breznitz D. Collaborative public space in a national innovation system: a case study of the Israeli military's impact on the software industry. Industry Innov 2005;12:31-64.

96. Jiggins J, Slobbe E, Roling N. The organisation of social learning in response to perceptions of crisis in the water sector of The Netherlands. Env Sci Pol 2007;10:526-36.

97. Oliver A, Montgomery K. Toward the construction of a profession's boundaries: creating a networking agenda. Human Rel 2005;58: 1167-84

98. Rose-Anderssen C, Allen P. Diversity and learning for innovation: dialogue for collaboration. J Manag Dev 2008;27:307.

99. du Toit M, Quayle M. Multiracial families and contact theory in South Africa: does direct and extended contact facilitated by multiracial families predict reduced prejudice? South Afr J Psychol 2011;41:540-51.

100. Santos F, Santos M, Pacheco J. Social diversity promotes the emergence of cooperation in public goods games. Nature 2008:454:213-16.

101. Mehra A, Dixon A, Brass D, et al. The social network ties of group leaders: implications for group performance and leader reputation. Organ Sci 2006;17:64.

102. Moynihan D, Pandey S. The ties that bind: social networks, person-organization value fit, and turnover intention. $J$ Public Adm Res Theory 2008;18:205.

103. McGrath C, Pate L, Gray E, et al. Getting wired for innovation: an analysis of the advice networks of software entrepreneurs. Int $J$ Organ Anal 2006;14:317.

104. Willem A, Buelens M. Knowledge sharing in public sector organizations: the effect of organizational characteristics on interdepartmental knowledge sharing. J Public Adm Res Theory 2007; $17: 581-606$.

105. Khoja F, Maranville S. The power of intrafirm networks. Acad Strategic Manag J 2009;8:51-70.

106. Obstfeld D. Social networks, the tertius iungens orientation, and involvement in innovation. Adm Sci Q 2005:50:100.

107. Bosson JK, Johnson AB, Niederhoffer K, et al. Interpersona chemistry through negativity: bonding by sharing negative attitudes about others. Personal Relationships 2006;13:135-50.

108. Chreim S. Social and temporal influences on interpretations of organizational identity and acquisition integration: a narrative study. J Appl Behav Sci 2007;43:449.

109. Hirst E, Vadeboncoeur JA. Patrolling the borders of otherness: dis/placed identity positions for teachers and students in schooled spaces. Mind Cult Activ 2006;13:205-27.

110. Kreiner G, Hollensbe E, Sheep M. On the edge of identity: boundary dynamics at the interface of individual and organizational identities. Human Rel 2006;59:1315-41.

111. Levine M, Prosser A, Evans D, et al. Identity and emergency intervention: how social group membership and inclusiveness of group boundaries shape helping behaviour. Pers Soc Psychol Bull 2005;31:443-53.

112. Tajfel H. Differentiation between social groups: studies in the social psychology of intergroup relations. London: Academic Press, 1978

113. Boyd R, Gintis H, Bowles S. Coordinated punishment of defectors sustains cooperation and can proliferate when rare. Science 2010;328:617-20.

114. Nowak M, Highfield R. SuperCooperators. New York: Free Press, 2011.

115. Petruzzelli AM, Albino V, Carbonara N, et al. Leveraging learning behavior and network structure to improve knowledge gatekeepers' performance. J Knowledge Manag 2010;14:635-58. 